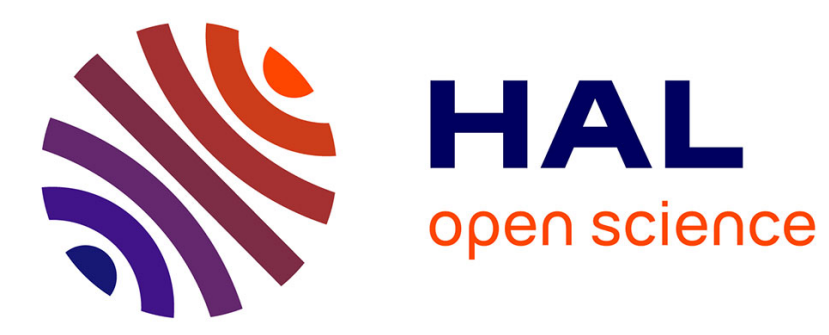

\title{
Effects of Electric Partial Discharges on the Rheological and Chemical Properties of Polymers Used in HV Composite Insulators after Railway Service
}

\author{
Jean-Pierre Habas, Jean-Marie Arrouy, Fabrice Perrot
}

\section{- To cite this version:}

Jean-Pierre Habas, Jean-Marie Arrouy, Fabrice Perrot. Effects of Electric Partial Discharges on the Rheological and Chemical Properties of Polymers Used in HV Composite Insulators after Railway Service. IEEE Transactions on Dielectrics and Electrical Insulation, 2009, 16 (5), pp.1444-1454. 10.1109/TDEI.2009.5293959 . hal-00709024

\section{HAL Id: hal-00709024 \\ https://hal.science/hal-00709024}

Submitted on 16 Jun 2012

HAL is a multi-disciplinary open access archive for the deposit and dissemination of scientific research documents, whether they are published or not. The documents may come from teaching and research institutions in France or abroad, or from public or private research centers.
L'archive ouverte pluridisciplinaire HAL, est destinée au dépôt et à la diffusion de documents scientifiques de niveau recherche, publiés ou non, émanant des établissements d'enseignement et de recherche français ou étrangers, des laboratoires publics ou privés. 


\title{
Effects of Electric Partial Discharges on the Rheological and Chemical Properties of Polymers Used in HV Composite Insulators after Railway Service
}

\author{
Jean-Pierre Habas \\ Institut Pluridisciplinaire de Recherche sur l'Environnement et les Matériaux, \\ Helioparc, 2 avenue Angot, \\ 64000 Pau, France \\ Jean-Marie Arrouy \\ ALSTOM Transport, \\ 50 rue du docteur Guinier \\ 65600 Semeac, France \\ and Fabrice Perrot \\ AREVA T\&D, \\ Technology Centre \\ Stafford, ST17 4LX, UK
}

\begin{abstract}
The origin and the consequences of the electric failure of in-service composite hollow insulators used in railway transportation were investigated. Direct electrical measurements made it possible the detection of partial discharges (PD) and UV emissions allowed of identifying the location of the PD at the interface between metal braids and a silicone liner. To investigate the effects of the damaging PD activity, physicochemical properties of the different polymers were investigated and compared to new samples. The thermomechanical properties of the HTV and RTV silicones showed important alterations in the polymers structure. The chemical analyses of the silicones and nitrile rubber conducted using ATR-FTIR spectroscopy revealed that the polymers were oxidized after electrical failure. The results indicated that the ozone production and UV emission were due to the surface electrical activities. The breakdown of alumina trihydrate (ATH) in the inner HTV silicone liner demonstrated that undesired electrical discharges induced an significant increase of temperature and the formation of moisture in the air present in the hollow insulator. Laboratory artificial aging performed on the silicones and nitrile rubber showed similar degradation as in service. Further electrical experiments conducted on empty hollow insulators enabled the detection of internal PD located in micro-voids present in the adhesive used to bond the HTV silicone liner to the inner composite tube.
\end{abstract}

Index Terms - Aging, composite, infrared spectroscopy, oxidation, ozone, partial discharges, silicone rubber, viscoelastic properties.

\section{INTRODUCTION}

POLYMERIC insulators have been increasingly used for the past 30 years in outdoor applications in a large range of medium and high voltage applications. In comparison with traditional glass or ceramic systems, composite insulators offer several advantages one of them being reduced weight. Their external

Manuscript received on 15 July 2008, in final form 7 April 2009. surface, usually made of a hydrophobic polymer provides better pollution performance and better resistance against vandalism caused by stone throws or gun shots. However, despite all these advantages, composite insulators have suffered in service from different failure modes [1]. Indeed, the overall quality of the composite insulators is strongly dependent on many factors such as the type of filler and the resin matrix [2,3], the interfacial properties $[4,5]$, the polymer surface roughness $[6,7]$ or the manufacturing conditions $[8,9]$. Besides structural parameters, 
the immediate environmental stresses can also be responsible for the electrical failure of composite insulators. For instance, epoxybased insulators are prone to water absorption in wet atmosphere, contributing to anomalous production of leakage currents [10-12] resulting in degradation. A more complex phenomenon called 'brittle fracture' is described by many researchers. It corresponds to the formation of stress corrosion cracks on the surface of the composite when subjected to an aggressive environment. Different mechanisms are proposed to explain brittle fracture, but the most likely is related to production of nitric acid solution induced by corona discharges in a high moisture environment [4, 13-16]. Other chemical species such as ozone or nitrogen also encourage the acid formation [17].

In railway transportation applications, non-ceramic insulators are often represented by hollow composites that comprise a central glass reinforced polymer (GRP) tube. This kind of design also includes many other materials such as an elastomeric housing (silicone, Ethylene-Propylene Diene Monomer EPDM, Ethylene Vinyl Acetate EVA, etc.) and metallic elements (connections, copper braids, etc.). The durability of this type of insulator is greatly complicated by various material interfaces between structural and external surface elements. In addition, these insulators are subjected during service to a large range of electrical, physical and chemical stresses and it is widely acknowledged that many degradation factors can be closely related to each other. For instance, anomalous electrical phenomena such as corona discharges can induce an excessive increase in temperature leading to thermal degradation of the surrounding materials. The same electrical activity can also cause a highly corrosive production of ozone [18-21]. These different interacting mechanisms tend to complicate the determination of the exact composite insulator failure mechanisms.

This paper presents a scientific methodology used to investigate the electrical failure associated with in-service composite hollow insulators used on $25 \mathrm{kV}$ traction switchgear. The originality of our approach is based on the association of electrical tests with FTIR and rheological analyses of the different polymeric materials used in the hollow insulator design. To establish a reliable failure pattern, we compared and analyzed the physicochemical characteristics of failed insulators after 8 months of service with the data obtained from new production units. Laboratory accelerated aging tests were also conducted to validate the failure mechanisms proposed.

\section{EXPERIMENTAL PROCEDURES}

\subsection{MATERIALS AND INSULATOR DESIGN}

The hollow composite insulators studied in this research were used in an outdoor railway transportation application (Figure 1). The design relied on a structural GRP composite manufactured by a glass filament winding technique (Figure 2). The external housing was made by a High Temperature Vulcanized (HTV) silicone rubber. The primary function of the HTV was to protect the GRP tube from moisture ingress. It also provided the external voltage creepage distance by increasing the composite resistance against pollution and the damaging effects of surface leakage currents. The same HTV silicone was also used for the internal lining of the GRP tube in order to prevent its hydrolysis and to reduce potential electrical erosion.

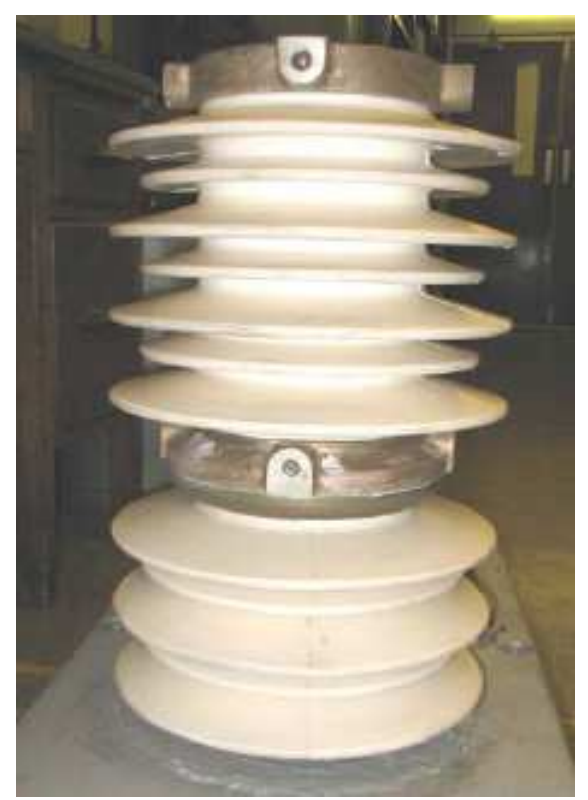

Figure 1. Overall view of the hollow insulator.

Other internal elements of the insulator included metal braids, Room Temperature Vulcanized (RTV) silicone and an elastomeric nitrile seal. On the basis of the above description, the construction of the composite hollow insulator had undeniably added complexity in terms of the range of materials used. It was evident that the insulator reliability would be dependent not only on the properties of the different elements but also it was likely to be affected by the numerous interfaces present including the enclosed airspace [22].

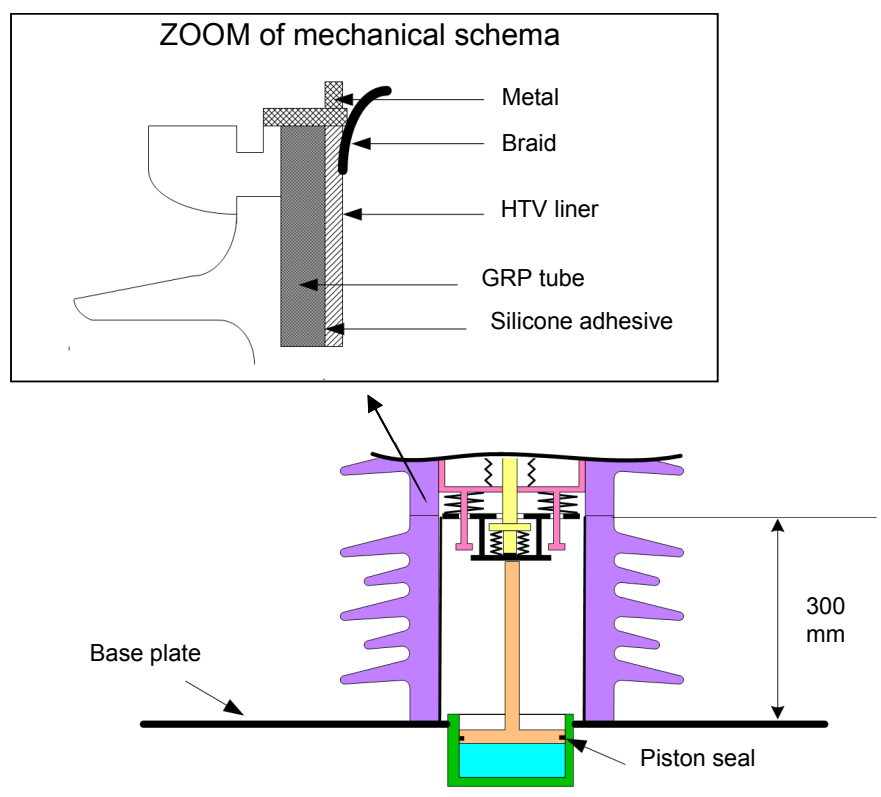

Figure 2. Cross-sectional representation of the hollow insulator studied in this research. 
All the polymer samples studied in this research were directly collected from failed insulators after service conditions and from new production units. A comparative investigation of both types revealed significant differences. In particular, the examination of the internal parts of failed hollow insulators showed extensive oxidation of all metallic elements such as copper connecting braids, electrodes and fasteners (Figure 3).

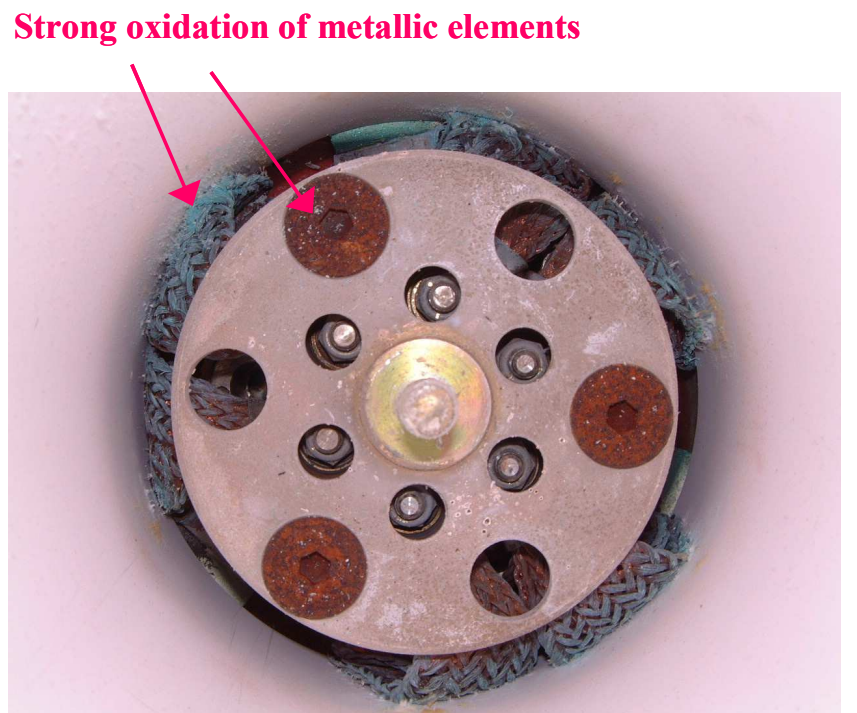

Figure 3. Visual inspection of the inner part of a failed insulator.

Further observations also indicated that several polymeric elements had severely degraded. Firstly, the elastomeric piston seal initially flexible had become hard and brittle and was now failing to seal efficiently (Figure 4).

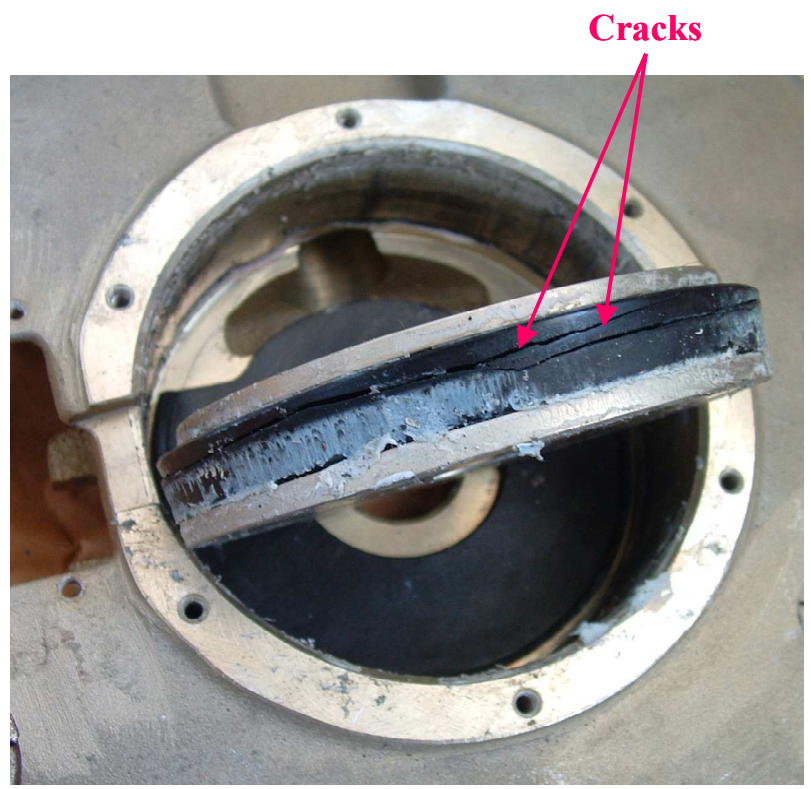

Figure 4. Evidence of cracks formation in the nitrile piston seal taken down from failed insulator.

Secondly, the inner HTV silicone liner was discolored from its original grey color to white. The discoloration was found to be inhomogeneous, it was much more pronounced on the surface in direct contact with the enclosed air (Figure 5).

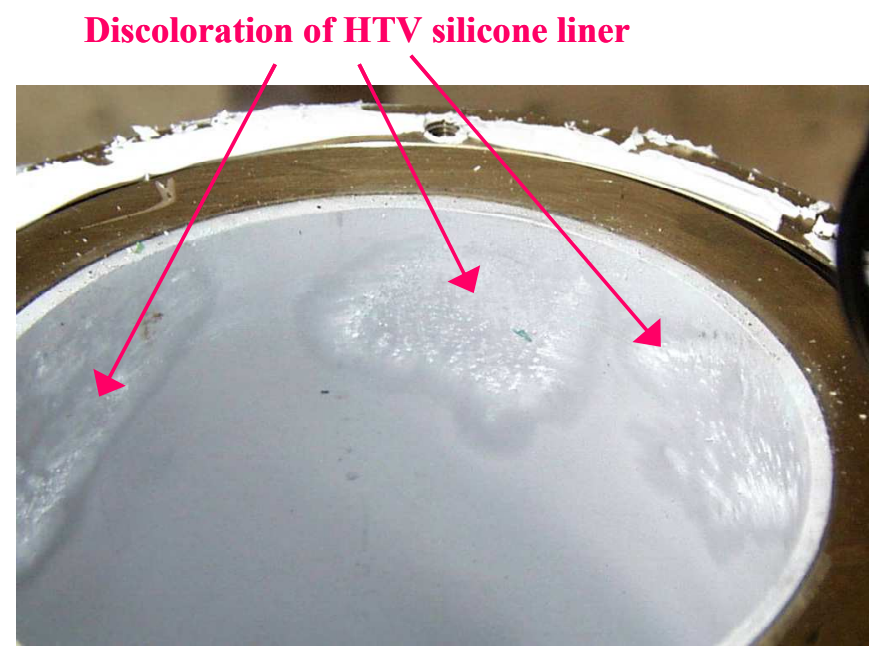

Figure 5. Evidence for HTV liner discoloration on failed insulator

Finally, the encapsulating RTV silicone was found to be tacky and could be easily torn compared to the initial elasticity of the polymer (Figure 6). These discrepancies supported the evidence that the deviation in the polymers' properties could not be attributed to differences in the chemical formulations.

\section{RTV gasket : change from elastic to pasty state}

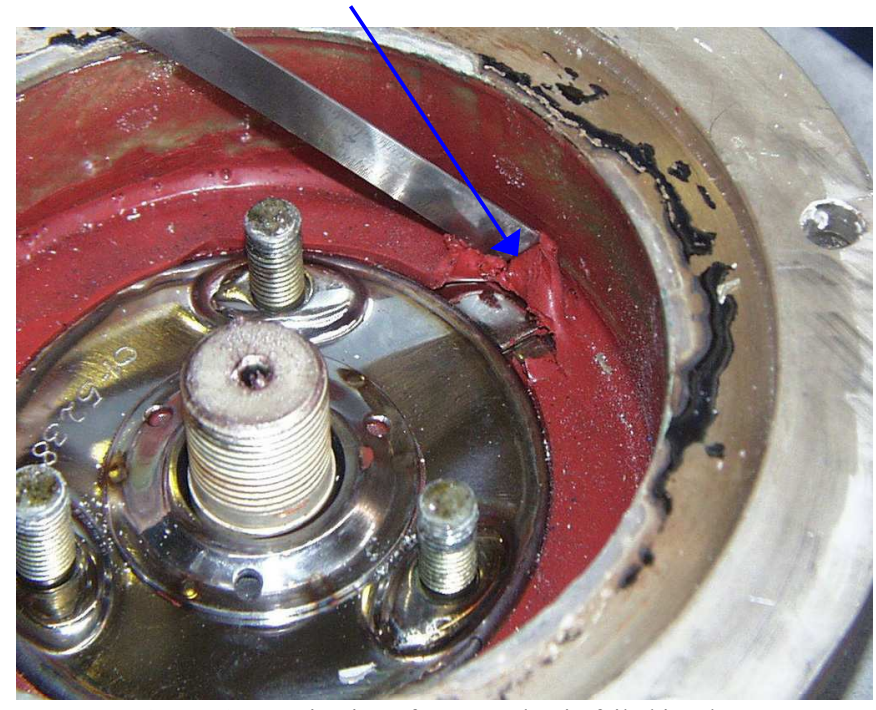

Figure 6. Examination of RTV gasket in failed insulator

\subsection{PARTIAL DISCHARGE DETECTION}

To quantify the failed insulators, partial discharge (PD) activity was measured using two experimental methods. The first one used a digital camera (Canon Powershot G5) which is sensitive to UV light emitted during PD to detect the location of the discharges in the central bore of the insulator [23]. During this experiment, the $\mathrm{AC} 50 \mathrm{~Hz}$ voltage, $\mathrm{U}$, was continuously increased from $1 \mathrm{kV}$ to $60 \mathrm{kV}$. The camera was set with an aperture opening of F8, an exposure time of 15 seconds and remotely triggered.

The PD activity within the insulators was also assessed up to $53 \mathrm{kV}$ using a direct PD detection technique. The voltage 
level and the PD magnitude were obtained using a Hipotronics DDX7000 Digital Discharge Detector, a 1000 pF $50 \mathrm{kV}$ blocking capacitor and a $100 \mathrm{pF} 100 \mathrm{kV}$ injection capacitor for the direct PD calibration. Each of the PD characterization tests were carried out by increasing the $\mathrm{AC}$ $50 \mathrm{~Hz}$ voltage up to a maximum of $53 \mathrm{kV}$, with the top and middle flange of the hollow insulator connected to the HV source and the lowest flange and base connected to ground. PD patterns were then recorded and analyzed. In particular, the PD patterns enabled the origin and location of the PD activity to be understood.

\subsection{FTIR ANALYSES}

The chemical changes in the composition and structure of the different polymers used in the composite insulator were determined using Fourier Transform InfraRed (FTIR) spectroscopy. The experiments were conducted on a Spectrum One spectrometer from Perkin Elmer. For most of the polymers studied (epoxy, HTV and RTV silicones), this apparatus was equipped with an Universal Attenuated Total Reflectance (ATR) accessory which was made of a diamond with a zinc selenide focusing element with a $45^{\circ}$ angle of incidence. In the case of the carbon black filled nitrile seal, a classic ATR made with a germanium crystal, more suitable for the study of highly absorbent materials, was used.

Both accessories enabled the measurements of the polymeric spectra by direct contact of the sample on the instrument crystal surface. Samples, therefore, did not require any preparation or modification and so the technique allowed adequate characterization of the polymeric samples following service conditions. Moreover, it is important to stress that these accessories were equipped with a pressure device that allowed the chemical characterization of the polymer to be reproducible. The experiment consisted in setting the sample on the crystal and to measure the optical absorption of a laser in the range 4000-650 $\mathrm{cm}^{-1}$. The absorbance spectrum was registered with a resolution of 4 $\mathrm{cm}^{-1}$ by adding 32 scans. In this spectrum, each absorbance band is characteristic by its position (wavenumber) and its amplitude (absorbance) of a precise chemical function. Thanks to a spectral table, it is possible to interpret the chemical composition and the nature of the material. The same technique is helpful to determine the structural changes caused by an aggressive medium or a contaminating environment.

\subsection{RHEOLOGICAL EXPERIMENTS}

The viscoelastic behaviour of HTV and RTV silicone samples were investigated as a function of temperature using a Rheometric Scientific ARES rheometer equipped with torsion fixtures. This configuration represented in Figure 7, required the preparation of the solid samples in rectangular form (40 $\mathrm{mm} \times 10 \mathrm{~mm} \times 2 \mathrm{~mm}$ ). The lower part of the tablet was attached to an actuator that forced an oscillating shear (dynamic mode). The upper part was attached to a sensor that measured the resulting stress due to the mechanical shearing of the sample.

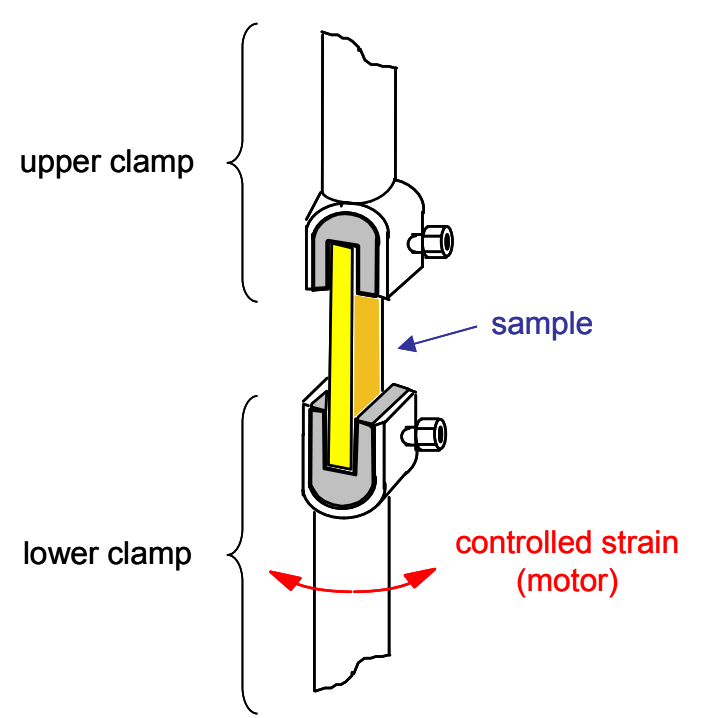

Figure 7. Schematic representation of rectangular torsion geometry used for thermomechanical analyses.

The nitrile seal could not be characterized by this method because of its specific geometry (o-ring) that could not be modified for rectangular torsion.

The rheometer was equipped with an environmental testing chamber that allowed temperature control. All the thermomechanical measurements were carried out in nitrogen over the temperature range -140 to $+150^{\circ} \mathrm{C}$ with a temperature ramp of $3^{\circ} \mathrm{C} / \mathrm{min}$ and a shearing frequency $\omega=1 \mathrm{rad} / \mathrm{s}$. The knowledge of the imposed strain and the measured stress allowed the calculation of the complex shear modulus $G^{*}=G^{\prime}+j G^{\prime}$. The component $G$ ', called "storage modulus", represents the mechanical rigidity of the sample whereas G" relates to the dissipated mechanical energy.

A thermomechanical analysis consists in measuring the evolution of the mechanical rigidity as a function of temperature. The same experiment is often used to determine the different critical temperatures characteristic of the material. For instance, the glass transition temperature that is specific of amorphous phases can be evaluated at the maximum of G" peak. The softening temperature, characteristic of crystalline regions is measured at the inflexion point where G' and G' curves strongly decrease.

The comparison of the thermomechanical profiles characteristic of new and aged samples is likely to evaluate the consequences of the industrial service. For instance, an alteration of the polymer skeleton should be observed through the evolution of one of the characteristics previously described (critical temperatures, rigidity...) Prior to each thermomechanical analysis, a strain sweeping experiment was carried out to determine the region where the polymer rheological response is linear. Normal force control was used throughout the test to keep the samples taut. Each experiment was repeated twice to verify the reproducibility of the rheological results.

\subsection{LABORATORY OZONE AGING}

New materials were exposed to ozone to investigate the evolution of their physicochemical behavior after aging. The experimental set-up used in the laboratory for the artificial production of ozone is described in Figure 8. 


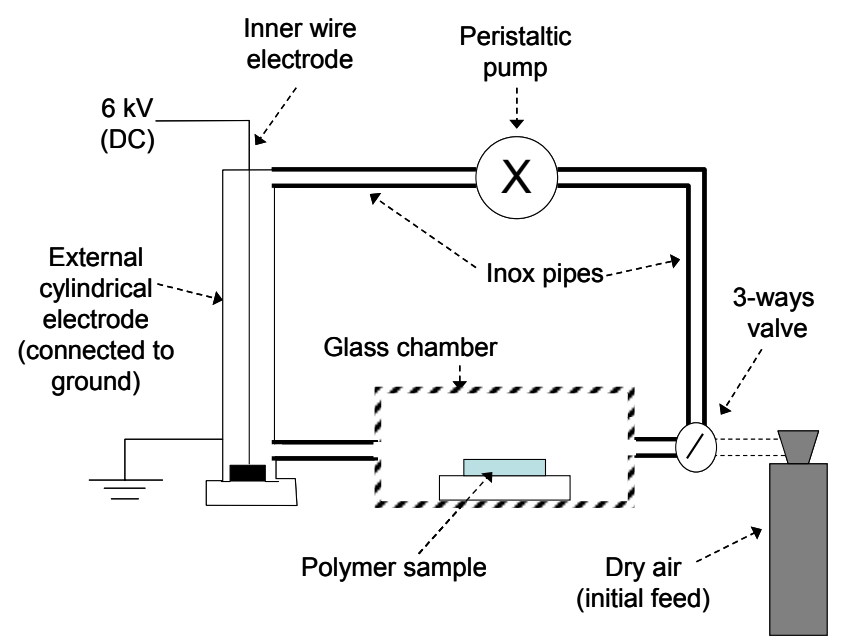

Figure 8. Details of the laboratory ozone chamber.

The procedure required to use dry air at ambient pressure for better yield. Once the air was injected, a 3-way valve was closed to force the gas circulation in closed loop using a peristaltic pump. Non-oxidizing pipes were used to convey the gas up to a "wire-cylinder" electrodes. Under a DC $6 \mathrm{kV}$ voltage, this electrical cell produced streamers that activated the chemical activation of the oxygen and its transformation into ozone. Then, this gas was injected in a glass chamber containing the polymer sample. The equilibrium ozone concentration (about $1000 \mathrm{ppm}$ ) was reached after 1 hour of closed circulation. After $200 \mathrm{~h}$ of aging time, the polymer sample was extracted from the ozone chamber just before its rheological characterization.

\section{RESULTS AND DISCUSSION}

\subsection{ELECTRICAL TESTS DIAGNOSTICS}

Optical PD measurements were carried out and as expected, the failed insulators showed poor electrical performances after service conditions. In particular, large surface discharges were detected at voltages as low as $12 \mathrm{kV}$, given that new device required a qualification voltage level above $30 \mathrm{kV}$. Similar experiments were also been carried out on new production insulators. A majority of them showed PD inception voltages in excess of $50 \mathrm{kV}$, but some were unable to be discharge free for voltages as low as $10 \mathrm{kV}$. The latter result clearly demonstrated that the origin of the electrical failure was unlikely to be related to excessive stresses during service conditions.

It is universally accepted that electric field enhancement near an HV electrode is often responsible for the initiation of corona discharges or surface discharge activity. Many factors can be responsible for this electric field enhancement, such as, electrode geometry, surface roughness, protrusions and also macroscopic impurities [24]. In the present study, the optical measurements pinpointed the exact location of the corona and surface discharges (Figure 9). The undesirable electrical activity was detected between a metal braid and the HTV silicone liner which was defined as a triple point "metaldielectric-air" [25].
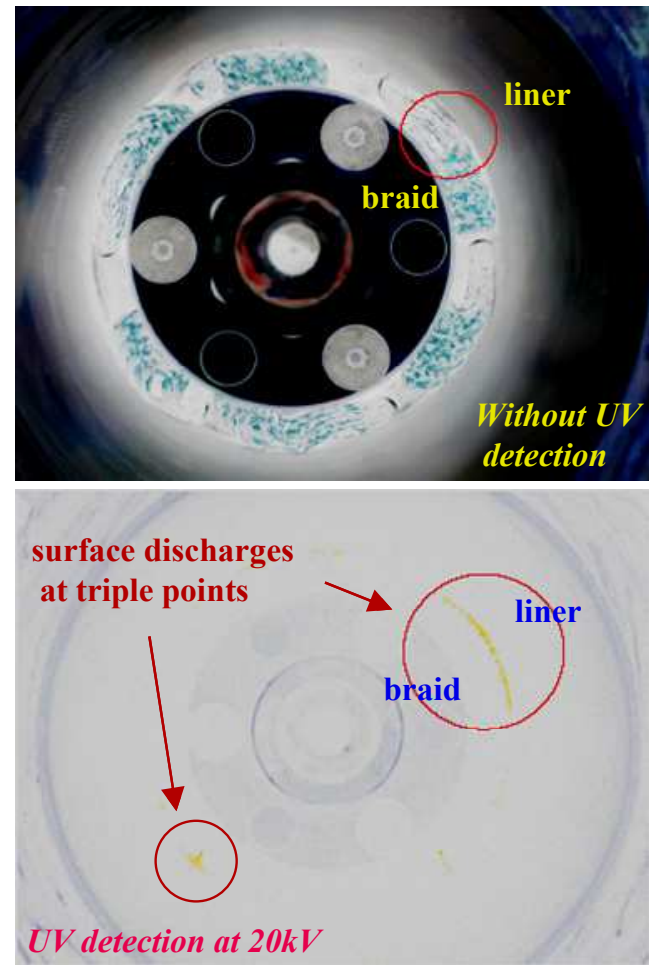

Figure 9. Optical PD measurements within the hollow insulator: experimental evidence of UV emission at "metal-dielectric-air" interfaces.

Direct electrical PD detection was also carried out in conjunction with the previously described optical measurements on the same hollow insulators. Each PD pattern represented the PD activity recorded over ten $50 \mathrm{~Hz}$ cycles. On one hand, the composite insulators that exceeded qualification voltage, produced corona discharges on the metal electrode system connected to the HV side of the hollow insulator. This phenomenon referred as "negative corona" is depicted by Figure 10a.
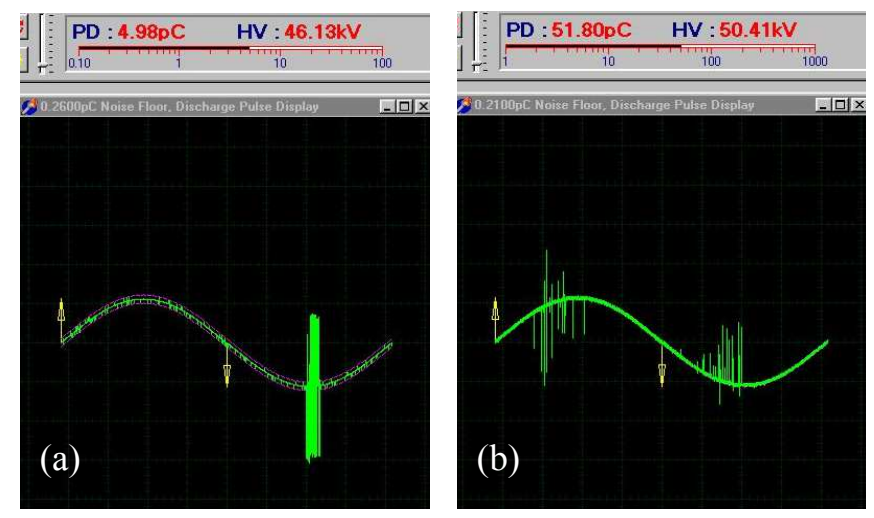

Figure 10. Direct PD Detection within the hollow insulator. Negative corona discharge (a), Internal / Surface PD activity (b).

On the other hand, failing hollow insulators produced an asymmetric PD pattern as shown in Figure 10b. This result was thought to be consistent with previous optical PD 
measurements that detected surface discharges in the vicinity of the metal electrode and the dielectric boundary (triple point). The shape of the PD pattern also suggested electrical discharges may be occurring in voids in either the HTV liner, its interface or within the composite tube.

\subsection{RHEOLOGICAL CHARACTERIZATIONS}

In order to investigate the origin and consequences of the damaging PD activity, the viscoelastic properties of the polymeric materials in direct contact with the inner part of the GRP tube were assessed. The first experiments concentrated on the HTV silicone liner. This elastomer was processed by the crosslinking of the uncured silicone resin previously poured in a cylindrical mould. The heating at $T=170^{\circ} \mathrm{C}$ enabled the transition from a viscous paste to a solid by formation of a three-dimensional polymeric network according the reaction diagram described in Figure 11.

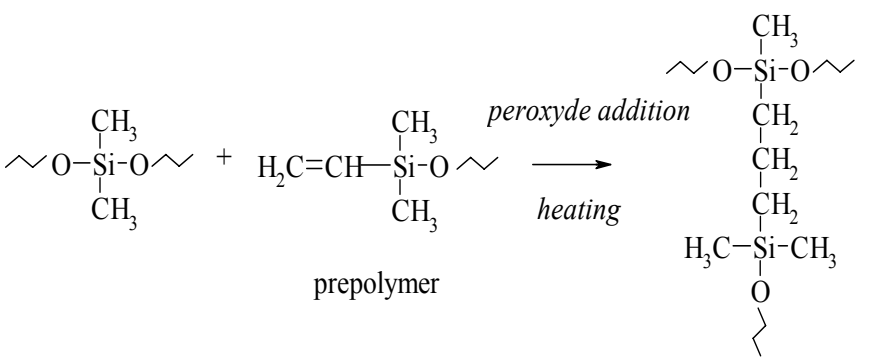

crosslinked polymer

Figure 11. Polymerization mechanism of HTV thermosetting silicone resin.

The rheological properties of the initial cured HTV elastomer as a function of temperature are described in Figure 12. The registered thermomechanical profile clearly showed that the polymer had a semi-crystalline morphology. In the low temperature region, the material was found to be quite rigid $\left(G^{\prime}>10^{9} \mathrm{~Pa}\right)$. More precisely, at $T=-115^{\circ} \mathrm{C}$, the curve of the elastic modulus $G$ ' showed a deflection while the $G$ ", curve presented a relaxation peak. This latter phenomenon is characteristic of the mechanical relaxation of the amorphous chains during the glass transition of the polymer. The decrease of the shear modulus with temperature remained limited up to $T=-50^{\circ} \mathrm{C}$ due to the persistence of the crystalline regions. Above this critical temperature, the softening of the crystalline phase was observed, giving the material a rubbery state. The elastomeric character then became predominant and the rheological properties remained temperature independent up to $150^{\circ} \mathrm{C}$. It has to be noted that the latter temperature widely exceeds the thermal range of the hollow insulator system in normal service conditions.

The thermomechanical behavior of the discolored HTV liner recovered from a failed hollow insulator after service conditions is also presented in Figure 12. It slightly differed from the previous results on a fresh polymer. In particular, the magnitude of the relaxation peak $(G$ ”), associated with the glass transition, was smaller and its maximum shifted to a lower temperature. Moreover, the polymer rigidity in the elastomeric state was significantly lower.

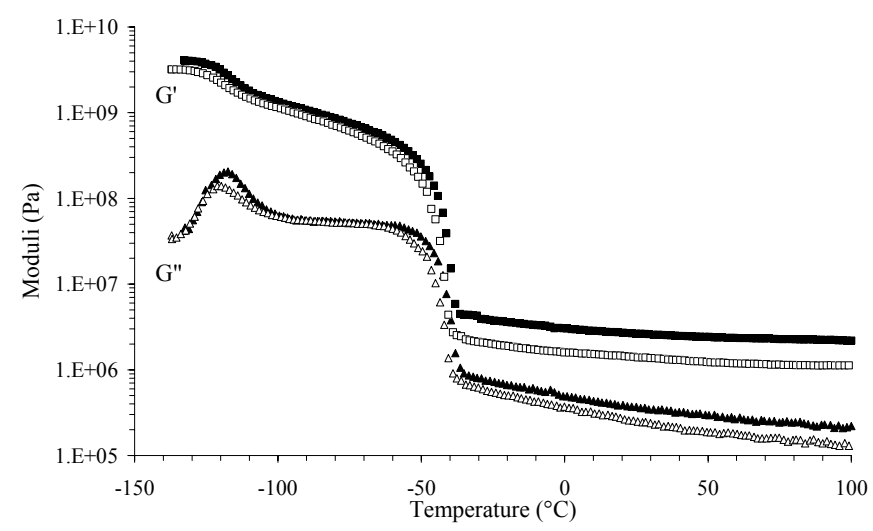

Figure 12. Thermomechanical behaviour of HTV silicone liner: new sample (full symbols) and after service conditions (empty symbols).

Similar changes were observed with the RTV silicone elastomer used in the hollow insulator as a flexible gasket. Figure 13 shows that the initial thermomechanical properties of the RTV silicone resemble that of the new HTV liner (full symbols). However, although the glass transition temperature and softening point were almost identical between both materials, the elastomeric rigidity of the RTV silicone at room temperature was about a decade lower.

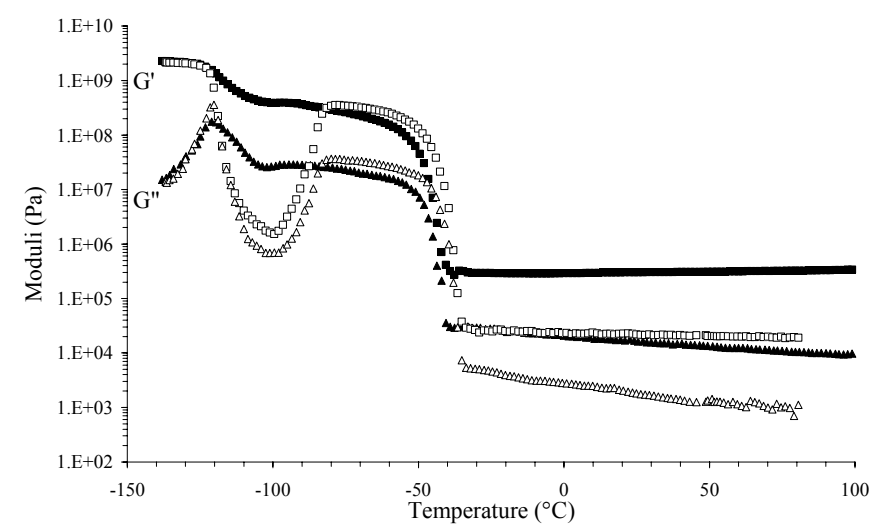

Figure 13. Thermomechanical responses of RTV silicone gasket: new sample (full symbols) and after eight months in service (empty symbols).

Figure 13 also reveals that the rheological properties of the aged RTV significantly differ from the characteristics of new samples. In particular, the rubber elasticity measured at temperatures $T>-50{ }^{\circ} \mathrm{C}$ was reduced from $3 \times 10^{5} \mathrm{~Pa}$ to $2.2 \times 10^{4}$ $\mathrm{Pa}$. But, according the classical theory of rubber elasticity, the mesh size of the polymer network is inversely proportional to the rubbery elasticity $G_{e}^{\prime}$ according the following equation:

$M c=\frac{\rho R T}{G_{e}^{\prime}}$

where $\rho$ is the density $\left(\mathrm{kg} \cdot \mathrm{m}^{-3}\right), R$ the gas constant $(8.31 \mathrm{~J} / \mathrm{mol} / \mathrm{K}), T$ the absolute temperature $(\mathrm{K})$ and $M c$ the average weight between junctions [26]. Then, for both silicones, the reduction of the value of the rubbery plateau appears to be consistent with the increase of the mesh size or in other words a depolymerization. These changes are likely due to the surface discharge activity within the hollow insulator during service conditions. 
Further observation of thermomechanical analyses seemed to validate the degradation of RTV and, to a lower extent, of HTV silicone. For instance, the decrease of the glass transition temperature was found coherent with the reduction of the crosslinking density as predicted by DiMarzio [27]. But, the most noticeable phenomenon was surely the presence of a depression in the rheological curves of aged RTV sample, just above the glass transition zone (Figure 13). Subsequently, both viscoelastic moduli newly increased to reach the crystalline plateau $\left(-80^{\circ} \mathrm{C}<\right.$ $\mathrm{T}<-50^{\circ} \mathrm{C}$ ). This latter evolution resembled that classically observed during a recrystallization. To go further in the understanding of this unexpected rheological behavior, a new thermomechanical analysis was undertaken on the same aged polymer but with decreasing temperature ramp. The results are described in Figure 14 that also reminds the data obtained with increasing temperature for easier discussion.

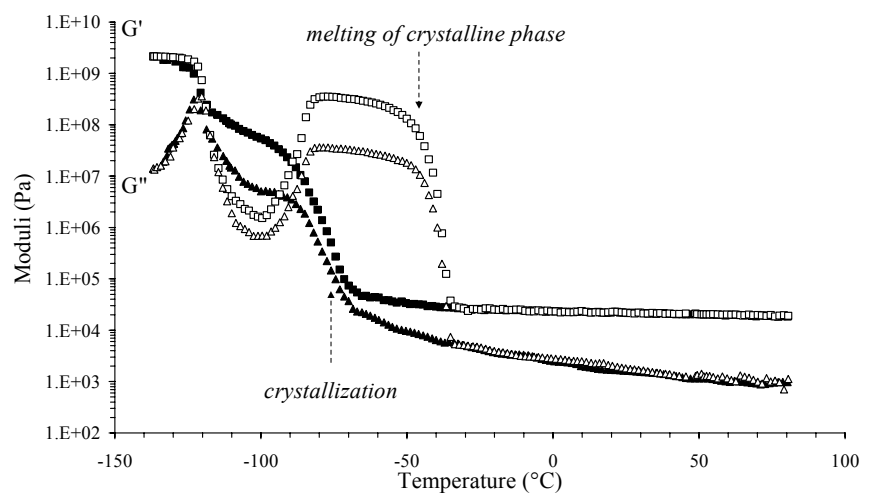

Figure 14. Thermomechanical analyses of aged RTV silicone: decreasing ramp $-3^{\circ} \mathrm{C} / \mathrm{min}$ (full symbols), increasing mode $+3^{\circ} \mathrm{C} / \mathrm{min}$ (open symbols)

Both analyses were perfectly superposed above the melting temperature of the RTV silicone $\left(T>-50{ }^{\circ} \mathrm{C}\right)$ where the polymer was in the rubbery state. For lower temperatures, the thermomechanical profiles were quite different due to the classical hysteresis between melting and crystallization temperatures: in decreasing mode the crystalline plateau was observed for $\mathrm{T}<-90^{\circ} \mathrm{C}$. Moreover, it presented a lower value than that observed in the analysis carried out with increasing temperature. This discrepancy suggested that the RTV silicone has been unable to fully crystallize with a temperature ramp fixed at $-3{ }^{\circ} \mathrm{C} / \mathrm{min}$. To observe a more complete crystallization, a smaller temperature ramp should have to be used in the decreasing mode to fit with the slow kinetic of the spatial organization of macromolecular chains. These latter results were judged as helpful to understand the origin of the depression observed in the rheological curves of the aged RTV silicone. During a temperature increase, the crystallization process should restart when the molecular mobility becomes sufficient (that is to say above the glass transition temperature). In other words, the depressions observed in Figures 13 and 14 can be interpreted as being representative of the chains' recrystallization provoked by an insufficient crystallization rate during the initial cooling of the polymer. This phenomenon could not be detected by calorimetry due to its weak exothermicity. As it mainly appeared with the aged RTV sample, it seemed to confirm that the degradation of this class of polymer was much more advanced than that observed with HTV aged sample: if the structural changes in both aged silicones produced an increase of the mesh size of the polymer network, the only crystallization kinetic of the RTV elastomer seemed affected.

\subsection{FTIR ANALYSES}

To investigate the structural origin of the rheological changes previously described, three different HTV silicone liners were analyzed by FTIR spectroscopy. The first sample was from a failed insulator which had been exposed to corona discharges, with an inception voltage (DIV) of $12 \mathrm{kV}$. The other samples were taken from HTV liners of new equipments but presented two distinct corona inception voltages (respectively $50 \mathrm{kV}$ and $10 \mathrm{kV}$ ). Figure 15 shows the different spectra obtained and translated along a vertical axis for clarity. As precised in the presentation of the experimental procedure, each spectral zone is specific of precise chemical groups. The first noticeable difference between all spectra was situated in the region (3200$3700 \mathrm{~cm}^{-1}$ - zone (1) that is characteristic of $\mathrm{OH}$ groups. As these units were not present in the chemical structure of silicone, they could be attributed to the only presence of alumina trihydrate $\mathrm{Al}(\mathrm{OH})_{3}$. This compound currently named ATH is used in the formulation of silicone to improve certain properties such as lower leakage currents, erosion-resistance or fireretardancy [28], [29]. Indeed, at temperatures exceeding $200{ }^{\circ} \mathrm{C}$, the breaking of ATH molecules generates new chemical species such as water and alumina [30]. The comparison of the different FTIR analyses showed that the intensity of the $\mathrm{OH}$ bands was much smaller in the case of HTV liner after service conditions. In other words, the ATH concentration was the most reduced for aged HTV elastomer. This ATH defect could be interpreted as being at the origin of the low value of the corona inception voltage as already proposed by Pradeep [33]. But, at the same time, one of the liners taken from new production presented an ATH concentration higher than that of the used liner whereas the respective insulator inception corona voltage was slightly lower $(10 \mathrm{kV}$ against $12 \mathrm{kV})$. From the above results, it is believed that the ATH concentration in the HTV silicone liner could be influenced by the surface discharge activity. This interpretation agreed with conclusions that have already been proposed in the literature by several authors [28-32].

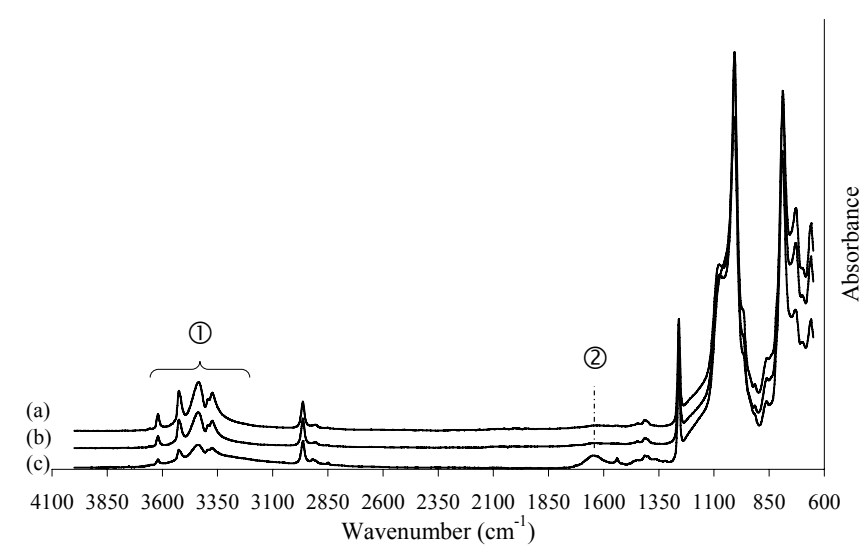

Figure 15. FTIR analyses of HTV liners. (a): liner DIV $50 \mathrm{kV}$ (new), (b): liner DIV $10 \mathrm{kV}$ (new) and (c): liner DIV $12 \mathrm{kV}$ (after service conditions). The spectra were arbitrarily shifted along vertical axis for clarity. 
The FTIR analysis of the HTV liner extracted from a failed insulator also exhibited the formation of carbonyl units as revealed by the increase of the absorbance band centered at $1628 \mathrm{~cm}^{-1}$ (Figure 15 - zone (2)). It is important to be reminded that these chemical species were not present in the initial HTV silicone structure. Additionally, their presence could not be explained by the ATH thermal transformation.

Such structural changes were also observed in the FTIR analyses of the nitrile piston seal which was found to be excessively brittle after service conditions (Figure 16). Indeed, the FTIR spectrum of the aged sample presented new absorbance bands located at 1257,1605 and $3350 \mathrm{~cm}^{-1}$ which were respectively representative of $\mathrm{C}-\mathrm{O}$ bonds, carbonyl $\mathrm{C}=\mathrm{O}$ groups and $\mathrm{OH}$ units.

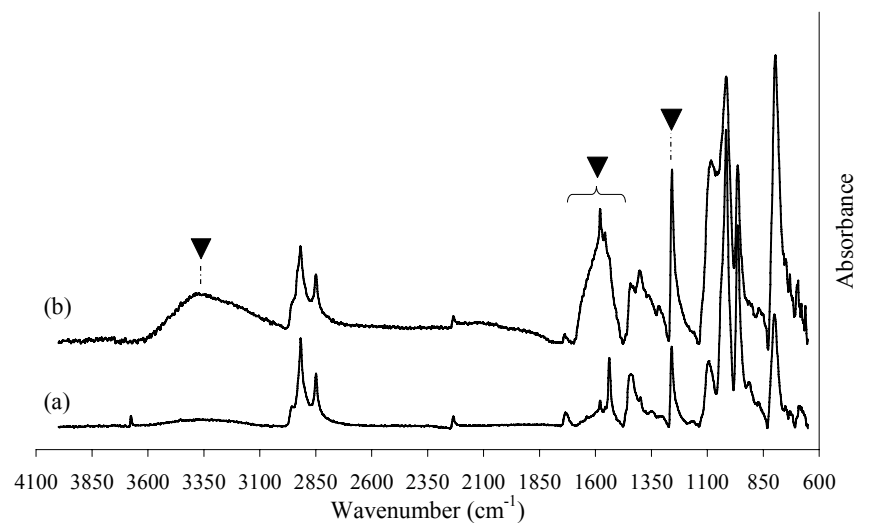

Figure 16. FTIR analyses of the nitrile piston seal. (a): new sample, (b): after failure in service. One spectrum was translated along a vertical axis for clarity.

\subsection{FAILURE MECHANISMS}

On the basis of our first experimental results, the premature failure of the hollow insulators has been related to the formation of corona discharges. These discharges were found at triple points formed by the air space surrounding the metal electrodes and the silicone elastomer liner. This undesirable electrical activity is well-known to inducing ozone production $[17,20,21$, $34,35]$. Moreover, the presence of this highly oxidizing gas within the hollow insulator was thought to be responsible for the corrosion observed on the metallic parts. It was also thought to induce the mechanical breaking of the nitrile piston seal, known for poor ozone resistance [36-38].

Understanding the degradation observed with the HTV and RTV silicones was more difficult due to the more generally accepted ozone resistance of this class of elastomers. In fact, controversy exists in the literature. On one hand, different mechanisms are suggested to explain the outstanding behaviour of silicones. One is based upon the fast conversion of polysiloxanes in silicon oxide units $\left(\mathrm{SiO}_{\mathrm{x}}\right)$ that permits the formation of a protective barrier with respect to ozone [39, 40]. A second concept proposes that the polymer is able to recover from its original properties by the diffusion of low molecular polysiloxane units toward the exposed polymeric surface [41, 42]. On the other hand, some researchers pointed out that the physicochemical properties of silicones can be slowly altered by ozone exposure. As an example, Shanbhag noted an important increase of oxidant gas permeability through aged silicone rubber [43]. Keshavaraj reported that the crosslink density of different silicone sealants decreased during the initial period of their exposure to ozone [44]. However, several experimental studies based on artificial accelerated aging tests showed that the oxidant action of ozone is higher when combined with UV light emission [45, 46]. Meng et al. proposed to interpret this phenomenon by the action of atomic oxygen produced in situ by photo-dissociation of ozone [39].

On the basis of all these studies, there is a certain debate on the behavior of silicone elastomers in oxidant medium. In our opinion, this is due to the great variety of silicone rubbers which can be divided in three main families: acid-type, RTV and HTV. Each of them is synthesized according to typical reactions that produce a thermoset polymer with specific properties. Additionally, it is impossible to generalize the experimental observations without clarifying the exact nature of the silicone studied and its physical state (prepolymer or crosslinked). In the framework of this study, the results obtained are consistent with the experimental data obtained by Homma et al. on both RTV and HTV silicones [47, 48]. Using gas chromatography/mass spectrometry (GC-MS) technique, the authors clearly demonstrated that field aged silicones suffered from depolymerization and oxidation when they are used in $\mathrm{HV}$ equipments.

To confirm or invalidate the influence of ozone on the properties of silicone samples studied, we carried out accelerated chemical aging of virgin RTV and HTV samples. The experimental procedure based on a laboratory ozone chamber has been previously described in part 3.5. The thermomechanical analysis of the exposed RTV silicone was worth noting since the rheological results showed a slight depression beyond the glass transition whilst the value of elastomeric elasticity decreased in comparison with the properties of the initial compound (Figure 17).

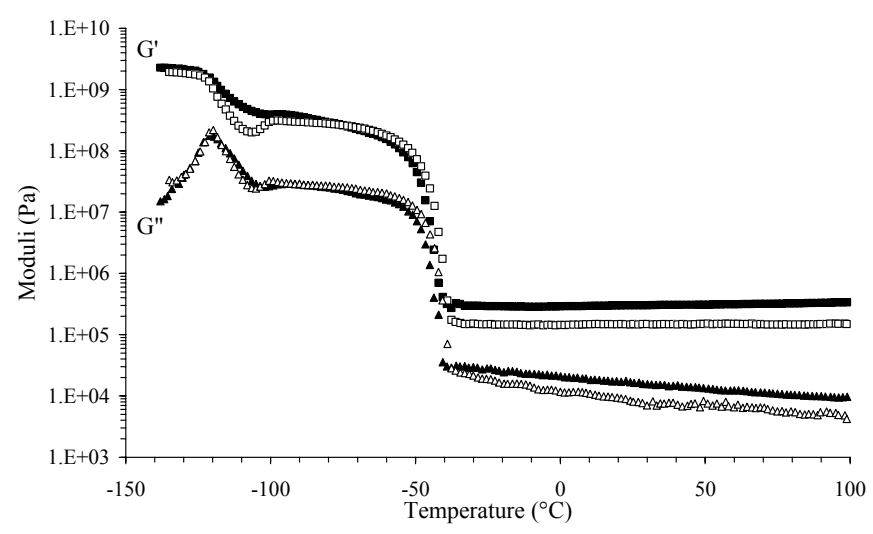

Figure 17. Thermomechanical analysis of RTV silicone: new sample (full symbols) and after artificial exposure to ozone (1000 ppm - $200 \mathrm{~h}$ - empty symbols)

As described previously, all these changes were also observed in samples taken from failed hollow insulators after service conditions. This result shows that the properties of RTV silicone can be affected by ozone exposure In the 
case of the HTV silicone, less pronounced effects were obtained, which seems consistent with the limited changes in rheological properties observed after service conditions. However, the structural changes only related to the amorphous phase of the polymeric network as described before with silicones aged in commercial conditions. One could be tempted to interpret this result as being the demonstration that the crystalline regions are insensitive to ozone. The more reduced intermolecular space could also be used to justify that ozone diffusion is harder in crystalline phase. But, this analysis would be incorrect. Indeed, it is important to note that in the present industrial appliance, HTV and RTV silicones were always used for temperatures higher than $-40^{\circ} \mathrm{C}$. In the elastomeric state, the crystalline morphology did not exist anymore. As a consequence, our results showed that ozone was able to produce local degradations in the polymer network that induced an increase of the average mesh size. In the same time, these alterations were sufficiently important to affect the crystallization kinetic of RTV silicone chains as previously shown in Figure 14.

Although the origin of the corona discharges and their consequences on the materials inside the hollow insulator seem to be defined now, the electrical discrepancies between hollow insulators of the same design were thought to be significant. As a consequence, it was thought that another parameter was likely to be contributing. Further electrical experiments conducted on empty hollow insulators (i.e. not fitted with internal parts) enabled the detection of internal partial discharges. Additional structural examinations were undertaken and identified structural bulk defects that could explain the origin of the internal PD activity. Voids were detected in the adhesive used to bond the HTV liner to the composite GRP tube (Figure 18).

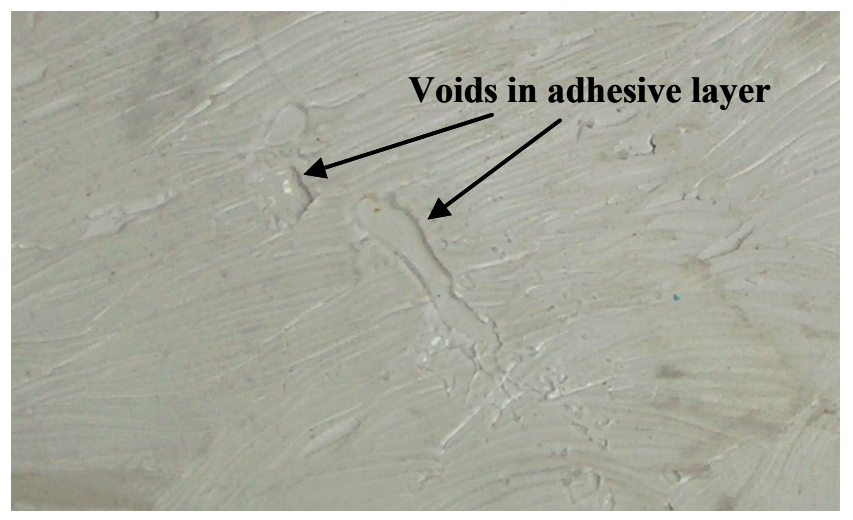

Figure 18. Presence of defects in the adhesive interface between the liner and the inner GRP tube.

Their influence on the electrical performances of the hollow insulator was considered to be significant. Internal PD activity was allowed to take place within the defects, thus affecting the electric field distribution along the internal length of the hollow insulator. This could also contribute to the generation of surface PD activity, reinforcing the production of ozone and UV emissions. These parasitic electrical activities (corona, internal and surface PD) were thought responsible for the previously suggested temperature increase and consecutive ATH breakdown in the HTV liner.

\section{CONCLUSIONS}

This paper showed that it was possible to identify the failure of traction hollow insulators by the combination of PD detection and physicochemical analyses of the different polymer materials used in the insulator design. A triple point junction identified within the hollow insulator (air, metal and silicone) was thought to be responsible for the formation of damaging corona discharges. This sustained PD activity resulted in the UV emissions and probably in ozone formation which led to the degradation of the different elastomers within the hollow insulation. The oxidation of silicones and nitrile rubbers was observed from visual inspections and confirmed by FTIR analyses. The same technique showed that the electrical discharges resulted in the breakdown of the alumina trihydrate filler within the HTV liner due most likely to the important localized increase in temperature. The generated moisture consequently accelerated, increased and sustained the discharge activity. The rheological experiments also pointed out that the parasitic electric activity was likely responsible of the depolymerization of the silicone rubbers. The changes within the polymeric network were much more important for the RTV than for the HTV samples. Indeed, the overall alterations of RTV silicones were judged to be sufficient to affect the propensity of the macromolecular chains to crystallize at very low temperatures. Artificial aging conducted on RTV and HTV virgin samples seemed to support the oxidant action of ozone. Finally, the detection of voids in the adhesive layer between the HTV liner and GRP tube explained the wide range of variations seen at the qualification stage of new insulators.

\section{ACKNOWLEDGMENT}

The authors would like to express their thanks to Dr. Jeremy Wheeler for the numerous fruitful scientific discussions.

\section{REFERENCES}

[1] M. Amin, M. Akbar, and M. Salman, "Composite insulators and their aging: an overview”, Sci In China Series E-Techno Sci, Vol. 50, pp 697713, 2007.

[2] A. Chateauminois, B. Chabert, J.P. Soulier, and L. Vincent, "Hygrothermal aging effects on the static fatigue of glass/epoxy composites", Composites, Vol. 24, pp. 547-555, 1993.

[3] J. Lanteigne, and C. de Tourreil, "The mechanical performance of GRP used in electrical suspension insulators", Computers \& Mathematics with Applications, Vol. 11, pp. 1007-1021, 1985.

[4] M. Kumosa, H. S. Narayan, Q. Qiu, and A. Bansal, "Brittle fracture of non-ceramic suspension insulators with epoxy cone end-fittings", Compos Sci Technol, Vol. 57, pp. 739-751, 1997.

[5] M.J. Owen, S.J. Harris, and B. Noble, "Failure of high voltage electrical insulators with pultruded glass fibre-reinforced plastic cores", Composites, Vol. 17, pp. 217-226, 1986. 
[6] R. Sundararajan R, E. Soundarajan, A. Mohammed, and J. Graves, "Multistress accelerated aging of polymer housed surge arresters under simulated coastal Florida conditions", IEEE Trans Dielectr. Electr. Insul, Vol. 13, pp. 211-226, 2006.

[7] L. Kumosa, D. Armentrout, and M. Kumosa, "The effect of sandblasting on the initiation of stress corrosion cracking in unidirectional Eglass/polymer composites used in high voltage composite (non-ceramic) insulators," Compos Sci Technol, 62, pp. 1999-2015, 2002

[8] L. Kumosa, D. Armentrout, B. Benedikt, and M. Kumosa, "An investigation of moisture and leakage currents in GRP composite hollow cylinders", IEEE Trans. Dielectr. and Electr. Insul, Vol. 12, pp. 1043$59,2005$.

[9] R.W. Harmon, G.G Karady, O.G. Amburgey, G. Gela, H. Schneider, J.T. Burnham, J. McBride, L. Coffeen, N. Spaulding, T. Carrera, Z. SziLagyi, J. Kuffel, R. Gemignani, J. Dushaw, R. Hambridge, A. Bernstorf and J. VanName, "Electrical test methods for non-ceramic insulators used for live line replacement", IEEE Trans. Power Delivery, Vol. 12, pp. 965970, 1997.

[10] V. Pauchard, F. Grosjean, H. Campion-Boulharts, and A. Chateauminois, "Application of a stress-corrosion-cracking model to an analysis of the durability of glass/epoxy composites in wet environments", Compos Sci Technol, Vol. 62, pp. 493-498, 2002.

[11] R.S. Gorur, B. Mobasher, M. Kumosa, L. Kumosa, and D. Armentrout, "Can water cause brittle fracture failures of non-ceramic insulators in the absence of electric field", IEEE Trans. Dielectr. Eletr. Insul, Vol. 12, pp. 621-626, 2005.

[12] L. Kumosa, D. Armentrout, B. Benedikt, and M. Kumosa, "An investigation of moisture and leakage currents in GRP composite hollow cylinders", IEEE Trans. Dielectr. Eletr. Insul, Vol. 12, pp. 1043-1059, 2005.

[13] A. Akhtar, and J.Y. Wong, "Failure analysis of brittle fracture in nonceramic insulators", J Compos Technol Res, Vol. 9, pp. 95-100, 1987.

[14] S.H. Carpenter, and M. Kumosa, "An investigation of brittle fracture of composite insulator rods in an acidic environment with static or cyclic loading”, J. Mater. Sci, Vol. 35, pp. 4465-4476, 2000.

[15] B. Noble, S.J. Harris, and M.J. Owen, "Stress corrosion cracking of GRP pultruded rods in acid environments", J. Mater. Sci, Vol. 18, pp. 12441254,1983

[16] S.N. Sapalidis, P.J. Hogg, and S.J. Youd, "High temperature acidic stress corrosion of glass fibre composites, Part I. Effect of fibre type", J. Mater Sci, Vol. 32, pp. 309-316, 1997.

[17] A.R. Chughtai, D.M. Smith, and M. Kumosa, "Chemical analysis of a field failed composite suspension insulator", Compos Sci. Techn, Vol. 58, pp. 1641-1647, 1998.

[18] M. Ehsani, G.R. Bakhshandeh, J. Morshedian, H. Borsi, E. Gockenbach, and A.A Shayegani, "The dielectric behavior of outdoor high-voltage polymeric insulation due to environmental aging", European Trans. Electr. Power, Vol. 17, pp. 47-59, 2007.

[19] B. Pinnangudi, R.S. Gorur, and A.J. Kroese, "Quantification of corona discharges on nonceramic insulators", IEEE Trans. Dielectr. Electr. Insul, Vol. 12, pp. 513-523, 2005.

[20] V.M. Moreno, R.S. Gorur, and A. Kroese, "Impact of corona on the long-term performance of nonceramic insulators", IEEE Trans. Dielectr. Electr. Insul, Vol. 10, pp. 80-95, 2003.

[21] M.EM. Horwitz, S.G. Horwitz, and C.M. Horwitz, "Corona emission and ozone production by carbonized and oxidized high-voltage wires", IEEE Trans. Power Delivery, Vol. 21, pp. 1636-1640, 2006.

[22] H. Janssen, J.M. Seifert, and H.C. Karner, "Interfacial phenomena in composite high voltage insulation”, IEEE Trans. Dielectr. Electr. Insul., Vol. 6, pp. 651-659, 1999.

[23] E.M. van Veldhuizen, and W.R. Rutgers, "Corona discharges: fundamentals and diagnostics", in Proceedings of Frontiers in Low Temperature Plasma Diagnostics, Limburg IV (Netherlands), pp. 40-49, 2001.

[24] F.H. Kreuger, "Partial Discharge Detection in High Voltage Equipment", London Boston, Butterworths \& Co. Publishers, 1989

[25] N.M. Jordan, Y.Y. Lau, D.M. French, R.M. Gilgenbach, and P. Pengvanich, "Electric field and electron orbits near a triple point", J. Appl. Phys., Vol. 102, art No.033301, 2007.

[26] J.D. Ferry, "Viscoelastic properties of polymers", $2^{\text {nd }}$ edition, Wiley \& Sons, 1969
[27] E.A. Di Marzio, "On second-order transition of rubber", J. Research National Bureau Standards, Vol. 68A, pp. 611, 1964.

[28] K. Siderakis, D. Agoris, and S. Gubanski, "Influence of heat conductivity on the performance of RTV SIR coatings with different fillers", J. Appl. Phys., Vol. 38, pp. 3682-3689, 2005.

[29] S. Kumagai, and N. Yoshimura, "Polydimethylsiloxane and alumina trihydrate system subjected to dry-band discharges or high temperature - Part I: Chemical structure", IEEE Trans. Dielectr. Electr. Insul., Vol. 11, pp. 691-700, 2004.

[30] S. Kumagai, and N. Yoshimura, "Tracking and erosion of HTV silicone rubber and suppression mechanism of ATH", IEEE Trans. Dielectr. Electr. Insul., Vol. 8, pp. 203-11, 2001.

[31] T.G. Gustavsson, S.M. Gubanski, H. Hillborg, S. Karlsson, and U.W. Gedde, "Aging of silicone rubber under ac or dc voltages in a coastal environment", IEEE Trans. Dielectr. Electr. Insul., Vol. 8, pp. 10291039, 2001.

[32] S.H. Kim, E.A. Cherney, and R. Hackam, "Effects of filler level in RTV silicone-rubber coatings used in HV insulators", IEEE Trans. Electr. Insul., Vol. 27, pp. 1065-1072, 1992.

[33] M.A. Pradeep, N. Vasudev, P.V. Reddy, and D. Khastgir, "Effect of ATH content on electrical and aging properties of EVA and silicone rubber blends for high voltage insulator compound", J. Appl. Polymer Sci, Vol. 104, pp. 3505-3516, 2007.

[34] M.W. Urban, and M.T. Stewart, "DMA and ATR FT-IR studies of gas plasma modified silicone elastomer surfaces", J. Appl. Polymer Sci, Vol.39, pp. 265-283, 1990.

[35] R. Ono, and T. Oda, "Spatial distribution of ozone density in pulsed corona discharges observed by two-dimensional laser absorption method", J. Phys. D, Appl. Phys., Vol. 37, pp. 730-735, 2004.

[36] M.P. Anachkov, S.K. Rakovsky, R.V. Stefanova, and D.M. Shopov, "Kinetics and mechanism of the ozone degradation of nitrile rubbers in solution," Polym Degrad and Stab, 19 (4), pp. 293-305, 1987

[37] G.J. Lake, and P.G. Mente, "Mechanisms of antiozonant protection of elastomers", Polym Degrad. and Stab., Vol. 49, pp. 193-203, 1995.

[38] F. Pruneda, J.J. Suno, F. Andreu-Mateu, and X. Colon, "Thermal characterization of nitrile butadiene rubber (NBR)/PVC blends", J. Thermal Analysis and Calorimetry, Vol. 80, pp. 187-190, 2005.

[39] O.Y. Meng, P.P. Klemchuk, and J.T. Koberstein, "Exploring the effectiveness of SiOx coatings in protecting polymers against photooxidation", Polym. Degrad. and Stab., Vol. 70, pp. 217-228, 2000.

[40] H. Hillborg, N. Tomczak, A. Olah, H. Schonherr, and G.J. Vancso, "Nanoscale hydrophobic recovery: A chemical force microscopy study of UV/ozone-treated cross-linked poly(dimethylsiloxane)", Langmuir, Vol. 20, pp. 785-794, 2004.

[41] L.K. Kim, and I.H. Kim, "Characteristics of surface wettability and hydrophobicity and recovery ability of EPDM rubber and silicone rubber for polymer insulators", J. Appl. Polym. Sci, Vol. 79, pp. 2251-2257, 2001

[42] A. Olah, H. Hillborg, and G.J. Vancso, "Hydrophobic recovery of UV/ozone treated poly(dimethylsiloxane): adhesion studies by contact mechanics and mechanism of surface modification", Appl. Surf. Sci., Vol. 239, pp. 410-423, 2005.

[43] P.V. Shanbhag, and K.K Sirkar, "Ozone and oxygen permeation behavior of silicon capillary membranes employed in membrane ozonators", J. Appl. Polym. Sci., Vol. 69, pp. 1263-1273, 1998.

[44] R. Keshavaraj, "Changes in cross-link density of structural silicone sealants due to ozone and moisture", Polym. Plast. Techn. Eng., Vol. 33, pp. 397-417, 1994.

[45] K. Efimenko, W.E. Wallace, and J. Genzer, "Surface modification of Sylgard-184 poly(dimethyl siloxane) networks by ultraviolet and ultraviolet/ozone treatment", J. Coll. Int. Sci, Vol. 254, pp. 306-315, 2002.

[46] Y. Israeli, J. Lacoste, J. Cavezzan, and J. Lemaire, "Photooxidation of polydimethylsiloxane oils and resins - effect of phenyl groups", Polym. Degrad. Stab., Vol. 47, pp. 357-362, 1995.

[47] H. Homma, T. Kuroyagi, K. Izumi, C.L. Mirley, J. Ronzello, and S.A. Boggs, "Evaluation of surface degradation of silicone rubber using gas chromatography/mass spectroscopy", IEEE Trans. Power Delivery, Vol. 15 , pp. 796-803, 2000.

[48] H. Homma, C.L. Mirley, J.A. Ronzello, and S.A. Boggs, "Field and laboratory aging of RTV silicone insulator coatings", IEEE Trans. Power Delivery,Vol.15, pp. 1298-1303, 2000. 


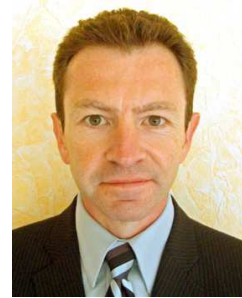

Jean-Pierre Habas was born in Orthez, France in 1969. He received in 1991 the M.Sc. degree (physics) and in 1992 a postgraduate degree (chemistry and physics) from the Université de Pau et des Pays de l'Adour. He graduated a Ph-D tesis in January 1995 from the UPPA, Pau, France, for researches conducted on the physicochemical properties of high temperature polymers. After military service, he was employed at the end of 1996 as associate professor in the LPMI, a laboratory specialized in polymers research in the University of Pau. In 2006, he joined the Pluridisciplinary Institute of Research on Environment and Materials (IPREM), Pau, where he is still working today. He is specialized in the study of polymers and composites for high performances applications (railway, aircraft transportation and HV civil engineering). He developed scientific and technical collaborations with several companies such as ALSTOM Transport, Hispano-Suiza, Thales, Messier Bugatti, Roxel, and AREVA. Its researches were applied for the packaging or electric encapsulation power-modules, the development of composites insulators, bus-bars and eco-friendly materials. Dr. Habas is a member of the Society of Plastics Engineers. Up to 2009, he directed 8 Ph-D, 3 post-doctorates and 9 research master studies. He wrote 20 papers in international journals, registered one patent about laser-soldering of high temperature thermoplastics for electronic and electrical packaging and also presented 21 international conferences in scientific congresses devoted to polymers and electrical engineering (ANTEC, INSUCON, IEEE International Conferences, IUPAC Macro).

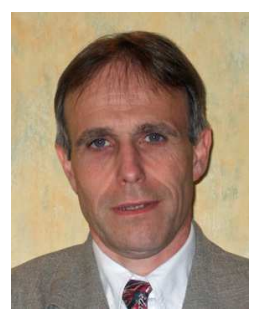

Jean-Marie Arrouy was born in Tarbes, France in 1960. He obtained in 1979 the "A" level (electrotechnics) in 1979. He graduated in 1994 a Coursework Masters degree in the Laboratoire de Génie Electrique, Pau, France and obtained in 1995 the Engineer degree in electrotechnics from the Conservatoire National des Arts et Métiers, Pau, France. After its military service in 1981, he was employed by Hugues tools enterprise and joined ALSTOM, Tarbes, in 1983 where he still has a position as engineer. He is specialized in the conception and development of railway equipment (HV switch gear, insulator, surge arrestor, control gear).Mr. Arrouy was member, up to 2000, of the scientific committee in charge of the redaction of CEI 60077 norms devoted to railway on-board railway switch gear. He is member of the ARC Electrique association that joins different French research laboratories and industries on HV applications. $\mathrm{He}$ is an expert in the detection, identification and quantification of electrical discharges.

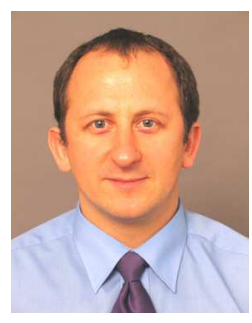

Fabrice Perrot was born in France in 1969. He graduated in electronics from the Université de Savoie, Annecy, France, from Brighton Polytechnic, UK, in High Voltage \& Power Systems in 1990 and received a $\mathrm{PhD}$ in 1995 from the University of Brighton for work on $\mathrm{ZnO}$ varistor materials. In 1994 he joined EA Technology Ltd, Capenhurst, UK and worked on HV outdoor insulation, moved in 1999 to the ALSTOM Research \& Technology Centre (now AREVA T\&D Technology Centre) in Stafford, UK and continues to work in HV technology and dielectric materials. Dr. Perrot is member of the IET but also belongs to the Scientific Committee of Electrotechnique du Future. He is Technical Chairman of the International Conference on Electrical Insulation (INSUCON). Fabrice manages the High Voltage and Electrical Materials Consultancy activity at the AREVA T\&D Technology Centre since 2004. He was recently appointed AREVA T\&D Senior Expert, is an active member of the IET in the UK. 